\title{
Lifelong approach to prevention and control of cardiovascular diseases - A road from theory to practice in the Federation of Bosnia and Herzegovina
}

\author{
Senka Mesihović-Dinarević1* , Aida Ramić-Čatak², Zaim Jatić3
}

'Department of Medical Sciences, Committee for Cardiovascular Pathology, Academy of Sciences and Arts of Bosnia and Herzegovina, Sarajevo, Bosnia and Herzegovina, ${ }^{2}$ Department fof Health Promotion and education, Institute for Public Health for Federation of Bosnia and Herzegovina, University of Sarajevo Faculty of Health Studies, Sarajevo, Bosnia and Herzegovina, ${ }^{3}$ Department for Family medicine, Medical Faculty Sarajevo University, Health Centre Sarajevo, Sarajevo, Bosnia and Herzegovina

\begin{abstract}
Cardiovascular diseases (CVDs) are the major cause of disability and premature death all over the world. Annually, 17.5 million people die from CVDs, representing 30\% of the total number of deaths. Despite the established guidelines for the treatment of acute coronary syndrome, cardiac weakness, atrial fibrillation, and CVD prevention, many patients remain inadequately treated, particularly in less developed nations. A brief overview of the development of CVDs, description of the current practice guidelines, and a cross-sectional analyses of the status of CVD prevention and control in the Federation of Bosnia and Herzegovina are given. In the past 7 years, there has been a steady increase in deaths, where half of all deaths in the Federation of Bosnia and Herzegovina are attributed to CVDs. Deaths from the acute myocardial infarction had a rate of 91.0/100,000 inhabitants, a significant increase compared to 2010 when this rate was 69.2. The second leading cause of death, a stroke, with a rate of 87.1 showed a slight decrease compared to 2010 when it was 89.9. The third leading cause of death, heart failure, with a rate of 68.4, has a slight decrease compared to 2010 when the rate was 75.7. CVDs are the leading cause of mortality in the Federation of Bosnia and Herzegovina, which, in addition to the large number of premature deaths, also causes major costs for the health sector and economy.
\end{abstract}

Key words: Cardiovascular disease; prevention; risk factors; monitoring; Bosnia and Herzegovina

\section{INTRODUCTION}

Cardiovascular diseases (CVDs) are the major cause of disability and premature death all over the world,

\footnotetext{
*Corresponding author: Senka Mesihovic-Dinarevic, Academy of the Sciences and Arts of Bosnia and Herzegovina, Bistrik 7, 71000 Sarajevo, Bosnia and Herzegovina.

E-mail: dsenka@bih.net.ba
}

Submitted: 26 January 2018/Accepted: 15 March 2018

DOI: https://doi.org/10.17532/jhsci.2018.528 contributing significantly to the rising costs of health care $(1,2)$. Around 17.5 million people die from CVDs in the world annually, representing $30 \%$ of the total number of deaths $(3,4)$. About 1.5 billion years of life are lost due to premature death and disability, and CVDs are responsible for 10\%. In Europe, CVDs are responsible for 4.9 million deaths annually, which is an average of $51 \%$ of all deaths $(1,2)$.

Despite the established guidelines for the treatment of acute coronary syndrome, cardiac weakness, atrial 
fibrillation, and CVD prevention, many patients remain inadequately treated, particularly in the southeastern Balkans. There have been sizable efforts to recognize CVD risk factors and enable timely diagnosis in Bosnia and Herzegovina through the primary health care system (PHC) (5). The aim of this paper was to summarize established guidelines in the prevention and monitoring of CVDs and to compare it to the trends in the Federation of Bosnia and Herzegovina, as well as to present the real challenges facing prevention and monitoring of CVDs in the Federation of Bosnia and Herzegovina.

\section{ETIOLOGY AND DEVELOPMENT OF CVDs}

The basic cause of the CVD development is atherosclerosis, which is the most common arterial disease characterized by the reduction in the lumen of the blood vessel due to local plaque or atheroma thickening. Of the ten most common causes of death, six are related to heart and blood vessels as a result of atherosclerosis $(10,11)$. Atherosclerosis begins in childhood, but the symptoms are not presented at the young age. Typically in the sixth decade of life, the symptoms appear and are exasperated with an increase in life expectancy. The most common risk factors for the development of atherosclerotic disease are hyperlipidemia, hypertension, smoking, diabetes, high fibrinogen, male and younger sex, menopause in women taking oral contraceptives or hormonal therapy only in the presence of other risk factors, increased weight, elevated level homocysteine, physical activity, inheritance, and immune response in some diseases $(12,13)$. The consequences of atherosclerosis include coronary or ischemic heart disease, in particular, myocardial infarction, cerebrovascular disease and cerebrovascular events $(80 \%$ of all myocardial infarction and stroke due to atherosclerosis), narrowing or blocking of peripheral arteries, and carotid arteries, especially leg, which can lead to gangrene development $(14,15)$.

\section{HISTORICAL PERSPECTIVE ON THE DEVELOPMENT OF CVD INTERNATIONAL PRACTICE GUIDELINES}

The CVD prevention guidelines have been published in numerous documents of internationally relevant organizations and associations including the World Health Organization (WHO), World Heart Federation, European Society of Cardiology and Other Societies on CVD Prevention in Clinical Practice, National Cardiac Societies, and others (16-17). The first recommendations of the European Society for the Prevention of CVD from 1994 reflected the need for consensus by the European Society of Atherosclerosis and the European Society of Hypertension and were aimed to assess the overall risk for primary prevention of CVD. The revision was published in 1998 by the involvement of these societies with the European Society of General Practitioners/Family Medicine, the European Heart Network (EHN), and the International Association of Behavioral Medicine. Realizing that even a wider field of expertise is needed, the European Association for the Study of Diabetes and the international diabetes federation have been included in the follow-up to the recommendations on CVDs, and the focus has been placed on the concept of the overall cardiovascular risk using the SCORE database (systematic coronary risk evaluation project).

Specific risk tables based on SCORE have been made for low- and high-risk countries and are widely accepted across Europe. The concept of the primary and secondary prevention was replaced by the knowledge that atherosclerosis is a continuous process. By incorporating the European Stroke Initiative in 2007, a fourth set of recommendations for the CVD was published by the combined effort of nine scientific bodies and the European Association for Cardiovascular Prevention and Rehabilitation within the ESC. In these recommendations, special emphasis was placed on the prevention of CVDs at the level of PHC and counseling on lifestyle changes, resulting in a revised approach to CVDs among young people using a relative riskbased table based on SCORE (18). The revised fifth set of the CVD recommendations focused on enforcing the dissemination of guidelines at the national level, the formation of national associations, and the implementation of recommendations in clinical practice.

The European Society of Cardiology and the EHN, with the support of the European Commission and the WHO, have developed the first European Heart Health Charter designed to prevent CVD in Europe. This public health document has been 
approved by most EU members underline a significance of healthy life choices. Millions of deaths all over the globe could be prevented through increasing services for smoking cessation, promotion of physical activity at least 30 min 5 times a week, promote a healthy eating habits and prevent obesity, monitoring of blood pressure below 140/90 $\mathrm{mm} / \mathrm{Hg}$, keep up a cholesterol $<5 \mathrm{mmol}(190 \mathrm{mg} /$ $\mathrm{dl})$, prevent of risk factors for diabetes and avoiding excessive daily stress (19).

The latest European guidelines were developed in 2016 by the Sixth European Joint Working Group and ten professional associations, entitled "2016 European guidelines on CVD prevention in clinical practice." For the purpose of simplification, the guidelines used a classification system based on the levels of evidence (A - evidence from meta-analysis, B - evidence from single randomized clinical trial, and $\mathrm{C}$ - opinion of experts) and classes of recommendation (I - general agreement that the procedure is beneficial, II - conflicting evidence, and III - general agreement that the procedure is not beneficial). It was developed for health professionals as a tool for better communication with individuals about their cardiovascular risk, benefits from a healthy lifestyle, and early modification of their cardiovascular risk. Compared to the previous ones, these new guidelines placed a greater emphasis on the population approach, i.e., women, young people, and ethnic minorities. A lifelong approach to the risk of developing CVD is important because the risk for CVD and prevention is dynamic and continuous, as patients' age and/or accumulate comorbidities. This means that, in addition to improve life and reduce risk factors in patients with established CVDs and those with an increased risk of developing CVD, healthy people of all ages should be encouraged to adopt a healthy lifestyle $(19,20)$.

Finally, it is important to note that the last decade of prevention and control of the CVDs has become a global public health challenge. For example, in 2011, thirty-eight contributors signed the Moscow Declaration on Non-communicable Diseases (NCD) as well as the UN Political Declaration on NCDs, which emphasized the urgency regarding the scale of the issues such as CVD, cancers, diabetes, and chronic lung disease $(5,6)$. Consequently, in 2013, the WHO adopted the Global Action Plan for the Prevention and Control of NCD for the period 2013-2020. The Global Action Plan provides Member States, international partners and WHO with a road map and menu of policy options which, when implemented collectively between 2013 and 2020, will contribute to progress on 9 global NCD targets to be attained in 2025 , including a $25 \%$ relative reduction in premature mortality from NCDs by 2025 (7-9).

\section{PREVENTION OF CVDS}

The position of the $\mathrm{WHO}$ is that over three-quarters of the total mortality from CVDs can be prevented by appropriate changes in lifestyle. CVD prevention is defined as a "coordinated set of activities at the public and individual levels, with the aim of eradicating, eliminating, or reducing the significance of CVDs and their disabilities" (9). The scientific evidence collected over the past decades has confirmed the enormous importance of CVD prevention that must be lifelong, from childhood to old age. Furthermore, prevention is effective: By eliminating behavioral risk factors, it is possible to prevent at least $80 \%$ of CVDs and even $40 \%$ of cancers (24).

An increased cardiovascular risk begins to develop in the early years of life. Even exposure to risk factors before birth can affect the risk of CVDs during their lifetime (21-23). Although children have a low absolute risk of developing CVDs, those with a relatively high risk compared to their peers, there remains an increased risk of cardiovascular events and later in life. A healthy lifestyle should begin as early as possible in childhood, creating healthy eating, eliminating smoking, and regular physical activity, which will prevent or slow down the development of atherosclerosis (24-26). The two primary goals of promoting cardiovascular health in children are preventing the development of risk factors associated with atherosclerosis (primordial prevention) based on general measures that focus on respecting a healthy lifestyle and the identification of a child at risk of developing early atherosclerosis due to the presence of identified risk factors, including hypertension, obesity, dyslipidemia, insulin resistance, physical inactivity, and exposure to tobacco smoke $(27,28)$. However, in most of the countries, the majority of the prevention of CVD is still focused on middle-aged or older men and women with existing CVD (i.e., secondary prevention) or 
those at high risk for the development of first cardiovascular events (e.g., men and women with combinations of smoking, elevated blood pressure, diabetes, or dyslipidemia [i.e., primary prevention]).

International experience has shown that the combinations of population strategies and strategies directed at high-risk individuals for CVDs are most effective (29). The population strategy aims to reduce the incidence of CVDs at the population level through a change in lifestyle and environmental factors focused on the population as a whole. This strategy is primarily achieved through the establishment of ad hoc policy and community-based activities. Examples include measures to stop smoking and reduce salt content in food. The advantage is that this method is of great benefit to the population. The impact of such an approach on the total number of CVDs in the population can be great because all subjects are targeted and most of the events just appear in people who are at a moderate risk. Interventions consist of the promotion of a healthy lifestyle, healthy eating, physical activity, quitting smoking, and drinking alcohol to a healthy environment (30). In a strategy targeting high-risk patients, preventive measures are aimed at reducing risk factors in those at the highest risk, whether they are individuals without CVDs at the upper percentiles of the total cardiovascular risk distribution or those with proven CVD. Interventions consist of CVD prevention in PHC, hospitalization, specialized prevention programs, and alternative rehabilitation models (30).

For a long time, the population strategy was considered more cost-effective than a strategy targeting high-risk patients, but since lipid-lowering drugs have been introduced, programs for smoking cessation and a reduced price of antihypertensive drugs have been introduced, and the effectiveness of a strategy targeting individuals at high risk is on the rise. Experience gained from long-term studies has reached a professional consensus: The greatest preventive effect in CVDs is achieved by combining the population and individual strategies $(29,30)$.

\section{OVERVIEW OF THE CVD TRENDS IN THE FEDERATION OF BOSNIA AND HERZEGOVINA}

The trends for the development of CVDs such as hypertension, smoking, alcohol consumption, diet, and physical activity are monitored regularly through periodic population surveys conducted by the Public Health Institute of the Federation of Bosnia and Herzegovina (31). The results of the population surveys from recent years will be discussed below; in general, they confirm the expression of a large number of risk factors for the development of CVDs in all population groups in the Federation of Bosnia and Herzegovina.

In 2002, the Population Health Survey on Risk Factors for CVD was conducted as part of the World Bank project and with the expert support of the Public Health Institute of Finland. The results of this study have shown the widespread presence of cardiovascular risks in the population, hypertension in $41.0 \%$ of the population, obesity expressed as $21.5 \%$, only $15.1 \%$ of the physically active population, and $37.6 \%$ of smokers (31).

In 2012, the Public Health Institute of the Federation of Bosnia and Herzegovina conducted a study that was supported by the World Bank on the health status of the population (35). This comprehensive analysis found an increase in risk factors for CVD development in the Federation of Bosnia and Herzegovina. Briefly, the study reported that almost half of adults or $42.1 \%$ have hypertension or are undergoing treatment, of which $45.3 \%$ are men and $38.9 \%$ are women. Almost half of the adult population or $44.1 \%$ are smokers, of whom $56.3 \%$ are men and $31.6 \%$ are women. Over half of the population or $54.1 \%$ are exposed to tobacco smoke on a daily basis by other smokers in indoor public spaces. Among school children aged 13-15 years, 12.7\% of smokers are recorded, and nearly two-thirds or $60.7 \%$ of children state that they are exposed to passive smoking in indoor public spaces. Furthermore, according to the same study, half of the adult population has a problem with inadequate nutrition, with $37.5 \%$ of the population being overweight and $22.5 \%$ obese. Physical activity is confirmed by a quarter of the population or $24.6 \%$ of population. The leading causes of death in the Federation of Bosnia and Herzegovina in 2016 were diseases of the circulatory system (I00-I99) with a share of 53.1\% of all causes (rate 508.2/100.000 inhabitants) and recorded a slight decrease compared to 2010 when the share was $53.8 \%$ with a rate of $472.1 / 100,000$ inhabitants (33). Regarding general mortality, the 
rate in 2016 was $956.6 / 100,000$ inhabitants, showing an increase compared to 2010, when it was $876.2 / 100,000$ inhabitants. Moreover, the standardized mortality rate for all causes and all ages for the Federation of Bosnia and Herzegovina shows a significant increase in 2016, namely 952.2/100.000 inhabitants and almost equaled the general mortality rate.

The data from 2016 listed myocardial infarction, stroke, and heart failure as the three leading causes of death in the Federation of Bosnia and Herzegovina. Deaths from the acute myocardial infarction had a rate of 91.0/100,000 inhabitants, which is a significant increase compared to 2010 when this rate was $69.2 / 100,000$ inhabitants. The second leading cause of death, a stroke, with a rate of 87.1/100,000 inhabitants showed a slight decrease compared to 2010 when it was 89.9. The third leading cause of death, a heart failure, with a rate of $68.4 / 100.000$ inhabitants, has a slight decrease compared to 2010 when the rate was 75.7/100.000 inhabitants. The fourth cause of death was cardiomyopathy with the rate of $63.9 / 100.000$ inhabitants, which is less compared to 2010 , when the rate was 78.7/100.000 inhabitants (33).

\section{PREVENTION AND CONTROL OF THE CVDS IN FEDERATION OF BOSNIA AND HERZEGOVINA}

This paper discussed some of systematic interventions made by the Federal Ministry of health, that focused on the prevention and control of CVDs in the Federation of $\mathrm{BiH}$, particularly due to the importance of preventing and controlling of risk factors for NCDs including CVDs as a one of the main causes of mortality in the Federation of $\mathrm{BiH}$ (34-39). They reached a conclusion that was in accordance with international guidelines, namely, to implement a strategy that consists of the population approach and the individual approach to high-risk individuals. This conclusion was in accordance with the reform of the PHC, which underwent major restructuring in the past decade through strengthening the concept of family or family medicine.

The PHC reform introduced the importance of the prevention and control of risk factors for CVDs. Thus, in accordance with the current health-care law, the family medicine team within the PHC provides continuous and comprehensive health care that is focused on the prevention and control of health factors and the early detection of disorders and diseases (35-37). As part of the mentioned reform, the Federal Ministry of Health has revised the plan and program for doctors who specialize in family medicine by introducing additional continuing education for work in the family medicine team, in which certain services include prevention and control of risk factors for chronic diseases and CVDs (41). However, even with the reform of the PHC, several population-based research studies in the Federation of Bosnia and Herzegovina pointed to inequalities in the availability of preventive health care for CVDs because PHC is still therapeutically oriented and heavily burdened by administration $(38,39)$.

Several studies and projects were conducted regarding prevention of risk factors in the Federation of Bosnia and Herzegovina. From 2005 to 2007, the Institute of Public Health of the Federation of Bosnia and Herzegovina in cooperation with the Federal Ministry of Health with the support of the Health Insurance Institute of Federation of Bosnia and Herzegovina conducted a pilot project focused on five risk factors (hypertension, obesity, unhealthy diet, smoking, and physical activity). The project was implemented through the work of 40 teams of family medicine in the Sarajevo Canton and the West Herzegovina Canton $(38,39)$.

In the period from 2013 to 2017, the project "strengthening and improving modern and sustainable public health strategies, capacities and services for improving the health of the population in Bosnia and Herzegovina" was launched in partnership with the Swiss Agency for Development and Cooperation (SDC), to support interventions in the prevention and control of chronic diseases in Bosnia and Herzegovina and the WHO Regional Office for Europe. The implementation of activities under this Project in the Federation of Bosnia and Herzegovina has been entrusted to the Public Health Institute of the Federation of Bosnia and Herzegovina in cooperation with the Federal Ministry of Health. Through component 2 of this Project, titled: "Adjustment/ development of instruments, materials and sets of indicators for implementation, monitoring and evaluation of interventions from the domain of 
risk assessment and CVD management (CVRAM), Institute for Public Health of the Federation of $\mathrm{BiH}$ in collaboration with Federal Ministry of Health initiated the activities of assessing the overall cardiovascular risk in the practice of family medicine, development of guidelines and protocols as procedures family medicine teams related to CVDs and risk factors, and the development of adequate educational materials for patients $(38,39)$.

Currently, an international project on oral and cardiovascular health has been initiated the Committee for Cardiovascular Pathology of the Department of Medical Sciences of the Academy of Science of Bosnia and Herzegovina. This ongoing project will provide a good basis for planning systemic interventions of the prevention of CVDs in Bosnia and Herzegovina.

Since the control of CVDs requires an adequate system of health-care and statistical reporting, the Public Health Institute of Federation of Bosnia and Herzegovina, in cooperation with the Federal Ministry of Health, initiated activities on the reform of the health-care statistical system with the aim of harmonization with internationally recommended indicators. The registry for CVDs at the federal and state levels has not yet been established, while the development of the diabetes registry is still in the initial phase. From 2012 to 2014, the Federal Ministry of Health supported by the World Bank created a study named Health Sector Strengthening Project that was implemented through family medicine teams with the aim of affirming the approach to screening of risk factors for patients aged 45-65 in the Federation of Bosnia and Herzegovina. The aim of the project was to develop adequate records and medical documentation mechanisms that should serve as the basis for improving the existing system of health statistical records $(38,39)$.

Health budgets in the Federation of Bosnia and Herzegovina cover the enormous costs of diagnosing and treating CVDs, while prevention and promotion of health are still viewed as an additional cost rather than a long-term and cost-effective investment in the health of citizens. Thus, according to the data of the Health Insurance Fund of Federation of Bosnia and Herzegovina, the number of patients who used cardiac and cardiovascular health services recorded steady growth from 4358 in 2011 to 5379 in 2015 as well as an increase in costs for these services in the amount of BAM 21,511,222 in 2011 to $25,140,839 \mathrm{KM}$ in 2015 (38).

To raise awareness among citizens about the importance of a healthy life by avoiding risk factors, the particular problem is the lack of continuous and intersectoral health promotion campaigns in Bosnia and Herzegovina, due in part to inadequate coordination between the sectors, mainly due to inadequate sources of funding. Less promotional interventions are implemented periodically by health institutions, public health institutes, and civil society, but this is still insufficient. Despite long public health advocacy efforts to divert part of the high tax tariffs, such as tobacco products into the health sector to finance systemic health promotion interventions, this intervention has not enforced in Bosnia and Herzegovina.

\section{GUIDELINES FOR CVDS IN THE FEDERATION OF BOSNIA AND HERZEGOVINA}

Over the past years, a number of project activities have been initiated in the health sector of the Federation of Bosnia and Herzegovina, through the support of relevant international organizations, which have been aimed at providing the basis for effective CVRAM. Within the framework of the project "Strengthening and improving modern and sustainable public health strategies, capacities and services for improving the health of the population in Bosnia and Herzegovina" in partnership with the SDC, the Public Health Institute and Federal Ministry of Health and Association of cardiologists of Bosnia and Herzegovina have published guidelines for diseases and cardiovascular risks, hypertension, diabetes, and dyslipidemia as well as also protocols for individual risk factors such as obesity in children and adults, physical activity of diabetes, and smoking, using the European Guide for the Prevention of CVDs in Clinical Practice (2012 version), developed by the European Society for Cardiovascular Prevention and Rehabilitation.

To support the effective use of these guidelines and guidelines for the prevention and control of CVDs, in 2017, about 1200 medical doctors and nurses in 
family medicine teams in the Federation of Bosnia and Herzegovina participated in the education that introduced and explained the importance of the mentioned guidelines. The education was organized by the Public Health Institute of Federation of Bosnia and Herzegovina in cooperation with the education centers of family medicine of the Health Centers in Sarajevo, Tuzla, Zenica, Mostar and Bihać.

\section{DISCUSSION}

CVDs have become a global public health challenge. As such, numerous efforts have been initiated by the UN and WHO to emphasize the importance of prevention and control of CVDs globally. The Moscow Declaration on NCD and UN Political Declaration on NCD have highlighted international cooperation and national efforts in the prevention of risk factors and in reducing disease and mortality from chronic diseases $(5,6)$. The WHO adopted the Global Action Plan for the Prevention and Control of NCD for the period 2013-2020. The main purpose of this document is assist to member states how to meet the achievement of 9 global for NCD by 2025 through the development and implementation of national policies, strategies and action plans to combat mortality from NCDs and particularly from CVDs (7-9). All scientific evidence collected through studies in recent decades have confirmed the enormous significance of CVD prevention that must be lifelong, which begins during pregnancy and lasts for the rest of their lives because an increased cardiovascular risk begins to develop in the early years of life. Even exposure to risk factors before birth can affect the risk of CVD during life (40-43). A healthy lifestyle should begin as early as possible in childhood, by creating healthy eating, eliminating smoking, alcohol, regular physical activity, and regular blood pressure, blood sugar, and blood lipid control, which can prevent or slow down the development of atherosclerosis as a risk factor for the development of CVDs (44-46).

The recommendations contained in the European Guidelines for CVDs point out that the greatest preventive effect is achieved by combining a population strategy and strategy directed at high-risk individuals. The population strategy aims to reduce the incidence of CVDs at the population level through a change in lifestyle, and environmental factors focused on the population as a whole. Interventions consist of the promotion of a healthy lifestyle, healthy eating, and physical activity, quitting smoking, and drinking alcohol to a healthy environment. In a strategy targeting high-risk patients, preventive measures are aimed at reducing risk factors for individuals at high risk for CVD or those with proven CVDs.

\section{CONCLUSION}

CVDs are the leading cause of mortality among the population of the Federation of Bosnia and Herzegovina, which, in addition to the large number of premature deaths, also causes major costs for the health sector and the community as a whole. The monitoring of trends of CVDs in Bosnia and Herzegovina is carried out through regular health statistics and periodic population surveys, with still a clear need to initiate a register for the CVDs in Bosnia and Herzegovina, to gain a more complete insight into the dimensions of this public health problem.

Over the recent years, in the health sector in the Federation of Bosnia and Herzegovina, numerous activities have been initiated with the aim of curbing the CVDs, which often remained after the completion of project initiatives remained limited to the level of individual cantons or health-care institutions. With the aim of supporting the systematic harmonization of the prevention and control measures of the CVDs in the Federation of Bosnia and Herzegovina, in the period from 2013 to 2017 Institute for Public Health in collaboration with Federal Ministry of Health supported by Swiss Goverment and WHO regional office for Europe, initiated the activities of publishing guidelines for CVDs and training of health profesionals in family medicine teams in the Federation of Bosnia and Herzegovina.

As it has been proven that exposure to risk factors before birth can affect the risk of CVD during the lifetime, prevention of CVDs must be based as a lifelong health promotion approach in all population groups and through whole life cycle. International research is underway on Oral and 
Cardiovascular Health, within the activities of the Committee for Cardiovascular Pathology of the Department of Medical Sciences of the Academy of Science of Bosnia and Herzegovina, in which results will surely provide good basis for planning systemic interventions for the prevention of CVDs in Bosnia and Herzegovina.

In further strengthening of the systematic prevention of risk factors for CVDs and developing the concept of health promotion, more efficient coordination and active participation of relevant institutions are needed, from the ministries of health, public health institutes, all levels of health care with a special focus on PHC, and family medicine teams, to the educational institutions at all levels and the patient association.

\section{REFERENCES}

1. World Health Organization. Causes of Death. Geneva: World Health Organization; 2008. Available from: http://www.who.int/healthinfo/global_ burden_disease/cod_2008_sources_methods.pdf. [Last accessed on 2018 Jan 20]

2. World Health Organization. Global Health Risks: Mortality and Burden of Disease Attributable to Selected Major Risks. Geneva: WHO; 2009.

3. World Health Organization. Global Status Report on Noncommunicable Diseases 2010. Geneva: WHO; 2010.

4. WHO. Global Atlas on CVDs Prevention and Control. WHO; 2011. Available from: http://www.who.int/cardiovascular_diseases/publications/ atlas_cvd/en. [Last accessed on 2018 Jan 20].

5. Resolution WHA61.14. WHO 2008-2013 Action Plan for the Global Strategy for Prevention and Control of Noncommunicable Diseases. Geneva: World Health Organization; 2008. Available from: http://www. who.int/nmh/publications/ncd_action_plan_en.pdf. [Last accessed on 2018 Jan 20].

6. Action Plan for Implementation of the European Strategy for the Prevention and Control of Noncommunicable Diseases 2012-2016, WHO Regional Office for Europe. Available from: http://www.euro.who.int/publications. [Last accessed on 2018 Jan 20].

7. Global Action Plan for the Prevention and Control of Noncommunicable Diseases 2013- 2020. Geneva: WHO; 2013. Available from: http://www. apps.who.int. [Last accessed on 2018 Jan 20].

8. UN Sustainable Development Goals 2015-2030 5. Noncommunicable Diseases Progress Monitor 2015, WHO Regional Office for Europe. Available from: http://www.euro.who.int/nmh/publications/ncd-progress-monitor-2015/en. [Last accessed on 2018 Jan 20].

9. The Main Indicators of the Global Monitoring framework (GMF) of Noncommunicable Diseases 2016, WHO Regional Office for Europe. Available from: http://www.euro.who.int/publications. [Last accessed on 2018 Jan 20]

10. Ross R. Atherosclerosis-an inflammatory disease. N Engl J Med 1999;340:115-26. https://doi.org/10.1056/NEJM199901143400207.

11. McGill HC Jr., McMahan CA, Zieske AW, Malcom GT, Tracy RE, Strong JP, et al. Effects of non-lipid risk factors on atherosclerosis in youth with a favorable lipoprotein profile. Circulation 2001;103:1546-50.

\section{https://doi.org/10.1161/01.CIR.103.11.1546.}

12. McGill HC Jr., McMahan CA, Malcom GT, Oalmann MC, Strong JP. Effects of serum lipoproteins and smoking on atherosclerosis in young men and women. The PDAY research group. Pathobiological determinants of atherosclerosis in youth. Arterioscler Thromb Vasc Biol 1997;17:95-106.

https://doi.org/10.1161/01.ATV.17.1.95.

13. Davis PH, Dawson JD, Riley WA, Lauer RM. Carotid intimal-medial thickness is related to cardiovascular risk factors measured from childhood through middle age: The Muscatine study. Circulation 2001;104:2815-9. https://doi.org/10.1161/hc4601.099486.

14. Mendis S, NordetP, Fernandez-Britto JE, Sternby N, For the Pathobiological Determinants of Atherosclerosis in Youth (PBDAY) Research group. Atherosclerosis in children and young adults: An overview of the world health organization (WHO) and international society and federation of cardiology study on pathobiological determinants of atherosclerosis in youth study (1985-1995). Prev Control 2005;1:3-15.

https://doi.org/10.1016/j.precon.2005.02.010.

15. Davis NE. Atherosclerosis-an inflammatory process. J Insur Med 2005;37:72-5.

16. Piepoli MF, Hoes AW, Agewall S, Albus C, Brotons C, Catapano AL, et al. 2016 European guidelines on cardiovascular disease prevention in clinical practice: The sixth joint task force of the European society of cardiology and other societies on cardiovascular disease prevention in clinical practice (constituted by representatives of 10 societies and by invited experts) developed with the special contribution of the European association for cardiovascular prevention and rehabilitation (EACPR). Eur Heart $J$ 2016;37:2315-81.

https://doi.org/10.1093/eurheartj/ehw106.

17. World Health Organization. Hearts: Technical Package for CVD Management in Primary Health Care. Geneva: World Health Organization; 2016.

\section{https://doi.org/10.1161/CIRCULATIONAHA.109.192703.}

18. Cardiovascular Disease Prevention: Public Health Guideline [PH25] Published date: June 2010. Available from: http://www.nice.org.uk/guidance/PH25. [Last accessed on $2018 \mathrm{Mar}$ 02].

19. Piepoli MF, Hoes AW, Agewall S, Albus C, Brotons C, Catapano AL, et al. 2016 European guidelines on cardiovascular disease prevention in clinical practice: The sixth joint task force of the European society of cardiology and other societies on cardiovascular disease prevention in clinical practice (constituted by representatives of 10 societies and by invited experts) developed with the special contribution of the European association for cardiovascular prevention and rehabilitation (EACPR). Eur Heart $J$ 2016;37:2315-81.

https://doi.org/10.1093/eurheartj/ehw106.

20. World Health Organization report on the Global Status Report on Noncommunicable Diseases. Published in 2010. Available from: http://www. apps.who.int/iris/bitstream/10665/44579/1/9789240686458_eng.pdf. [Last accessed on 2018 Mar 03].

21. Moran AE, Forouzanfar MH, Roth GA, Mensah GA, Ezzati M, Murray CJ, et al. Temporal trends in ischemic heart disease mortality in 21 world regions, 1980 to 2010: The global burden of disease 2010 study. Circulation 2014;129:1483-92.

https://doi.org/10.1161/CIRCULATIONAHA.113.004042.

22. Mesihovic-Dinarevic $S$. Prevention of cardiovascular disease from an early age. J Cardiovasc Dis Diagn 2017;5:268

https://doi.org/10.4172/2329-9517.1000268.

23. Dhuper S, Buddhe S, Patel S. Managing cardiovascular risk in overweight children and adolescents. Paediatr Drugs 2013;15:181-90.

https://doi.org/10.1007/s40272-013-0011-y.

24. Liu K, Daviglus ML, Loria CM, Colangelo LA, Spring B, Moller AC, et al. 
Healthy lifestyle through young adulthood and the presence of low cardiovascular disease risk profile in middle age: The coronary artery risk development in (Young) adults (CARDIA) study. Circulation 2012;125:996-1004. https://doi.org/10.1161/CIRCULATIONAHA.111.060681.

25. Berenson GS, Srinivasan SR, Bao W, Newman WP $3^{\text {rd }}$, Tracy RE, Wattigney WA, et al. Association between multiple cardiovascular risk factors and atherosclerosis in children and young adults. The Bogalusa heart study. N Engl J Med 1998;338:1650-6.

https://doi.org/10.1056/NEJM199806043382302.

26. Raitakari OT, Juonala M, Kähönen M, Taittonen L, Laitinen T, MäkiTorkko N, et al. Cardiovascular risk factors in childhood and carotid artery intima-media thickness in adulthood: The cardiovascular risk in young Finns study. JAMA 2003;290:2277-83.

https://doi.org/10.1001/jama.290.17.2277.

27. Lloyd-Jones DM, Leip EP, Larson MG, D'Agostino RB, Beiser A, Wilson PW, et al. Prediction of lifetime risk for cardiovascular disease by risk factor burden at 50 years of age. Circulation 2006;113:791-8. https://doi.org/10.1161/CIRCULATIONAHA.105.548206.

28. Puska P. From Framingham to north Karelia: From descriptive epidemiology to public health action. Prog Cardiovasc Dis 2010;53(1):15-20. https://doi.org/10.1016/j.pcad.2010.01.003.

29. Levi F, Chatenoud L, Bertuccio P, Lucchini F, Negri E, La Vecchia C, et al. Mortality from cardiovascular and cerebrovascular diseases in Europe and other areas of the world: An update. Eur J Cardiovasc Prev Rehabil 2009;16(3):333-50. https://doi.org/10.1097/HJR.0b013e328325d67d.

30. World Health Organization. Global Health Observatory Data Repository. Geneva: World Health Organization; 2008. Available from: http://www. apps.who.int/ghodata/, accessed 23.8.11.

31. Survey of the health status of the population of Federation of Bosnia and Herzegovina, 2002, Institute for Public Health of Federation of Bosnia and Herzegovina. Available from: http://www.zzjzfbih.ba. [Last accessed on 2018 June 20].

32. Study of the health status of the population of Federation Bosnia and Herzegovina, Institute for Public Health of Federation of Bosnia and Herzegovina; 2012. Available from: http://www.zzjzfbih.ba. [Last accessed on 2018 June 20]

33. Report on the health status of the population in Federation of Bosnia and Herzegovina 2016, Institute for Public Health of Federation of Bosnia and Herzegovina; 2012. Available from: http://www.zzjzfbih.ba. [Last accessed on 2018 June 20].

34. Strategy for PHC development in Federation of Bosnia and Herzegovina, Federal Ministry of Health. Available from: http://www.fmz.gov.ba. [Last accessed on 2018 Aug 20].
35. Law on Health Care (Official Gazette of Federation of Bosnia and Herzegovina 46/10). Available from: https://www.rm.coe. int/7th-national-report-from-bosnia-and-herzegovina/168075a485. [Last accessed on 2018 June 20].

36. Acreditation standards za Health Centres, AKAZ; 2010. Available from: http://www.akaz.ba. [Last accessed on 2018 June 20].

37. Acreditation Standards za Family Medicine Teams, AKAZ; 2014. Available from: http://www.akaz.ba. [Last accessed on 2018 June 20].

38. Federal Ministry of Health. Available from: http://www.fmz.gov.ba [Last accessed on 2018 Aug 20].

39. Institute for Public Health of Federation of Bosnia and Herzegovina; 2012. Available from: http://www.zzjzfbih.ba [Last accessed on 2018 June 20].

40. Urbina EM, Kieltkya L, Tsai J, Srinivasan SR, Berenson GS. Impact of multiple cardiovascular risk factors on brachial artery distensibility in young adults: The Bogalusa heart study. Am J Hypertens 2005;18:767-71.

https://doi.org/10.1016/j.amjhyper.2004.12.017.

41. Juonala M, Magnussen CG, Venn A, Dwyer T, Burns TL, Davis PH, et al. Influence of age on associations between childhood risk factors and carotid intima-media thickness in adulthood: The cardiovascular risk in young Finns study, the childhood determinants of adult health study, the Bogalusa heart study, and the Muscatine study for the international childhood cardiovascular cohort (i3C) consortium. Circulation 2010;122:2514-20. https://doi.org/10.1161/CIRCULATIONAHA.110.966465.

42. Vienna Declaration on Nutrition and Noncommunicable Diseases in the Context of Health 2020. Copenhagen: WHO Regional Office for Europe; 2013. Available from: http://www.euro.who.int/data/assets. [Last accessed on 2018 June 20].

43. Oguma $Y$, Shinoda-Tagawa T. Physical activity decreases cardiovascular disease risk in women: Review and meta-analysis. Am J Prev Med 2004;26(5):407-18.

https://doi.org/10.1016/j.amepre.2004.02.007.

44. Mukamal KJ, Chen CM, Rao SR, Breslow RA. Alcohol consumption and cardiovascular mortality among U.S. Adults, 1987 to 2002. J Am Coll Cardiol 2010;55:1328-35.

https://doi.org/10.1016/j.jacc.2009.10.056.

45. Rehm J, Baliunas D, Borges GL, Graham K, Irving H, Kehoe T, et al. The relation between different dimensions of alcohol consumption and burden of disease: An overview. Addiction 2010;105:817-43.

https://doi.org/10.1111/j.1360-0443.2010.02899.x.

46. Ronksley PE, Brien SE, Turner BJ, Mukamal KJ, Ghali WA. Association of alcohol consumption with selected cardiovascular disease outcomes: A systematic review and meta-analysis. BMJ 2011;342:d671.

https://doi.org/10.1136/bmj.d671. 